\title{
Sobre uma política equivocada
}

\author{
Harley E. A. Bicas
}

Entre os variados assuntos sobre os quais pode incidir a conveniência de comentários em editoriais de uma revista científica brasileira, alguns são mais reiteradamente suscitados, tais como o dos significados e consequências das chamadas indexações e fatores de impacto. Com efeito, eles compõem um conjunto de critérios pelos quais hoje se faz a avaliação de qualidade das publicações dessa natureza e, portanto, representam-lhes valores de interesse genuíno, factual. Simplesmente, não podem ser ignorados. Assim, embora em muitas ocasiões já se haja abordado essa temática e afins, nova oportunidade aparece para que a ela se retorne.

Uma especificação no período inicial talvez chame a atenção: “...revista científica brasileira". Por que "brasileira"? As dos demais países não seriam, igualmente, sujeitas às mesmas normas e condições? Não são elas universais e consensuais? Sim e não! "Sim", porque a idéia do fator de impacto, simples e objetiva, ainda que arbitrariamente proposta (seu próprio autor já admitiu os problemas que ela poderia trazer) está bem defendida e arraigada. Conquanto possa não convir às necessidades de países "emergentes", nem à realidade de suas revistas científicas, impôs-se de tal modo que se torna quixotesca qualquer tentativa de mudá-la. Por outro lado, "não", porque no Brasil as condições de valorização desses critérios ganharam uma conotação desproporcional às suas dimensões biblioteconômicas, passando a nortear políticas de fomento científico e a conduzir produções acadêmicas. Pior: agudizaram-se ultimamente. Realmente, os conceitos de indexação de uma revista científica e de seus fatores de impacto são os sustentáculos pelos quais ela é classificada pelo "Qualis".

Para quem não está imerso nas lides universitárias, "Qualis" é o conceito erigido pela CAPES para qualificar (daí o nome) revistas científicas, nacionais ou estrangeiras, e, em decorrência, a produção científica por elas publicada. O pressuposto - e, reconheça-se, com fundamentação aparentemente sólida - é o de que revistas de maior procura para a leitura e (supostamente) mais confiáveis em seus processos de seleção de artigos são, por isso, "melhores". Em consequência, atraem mais artigos e podem, de entre eles, selecionar os mais interessantes por sua originalidade ou confecção, continuando, assim, "melhores". Em suma, são qualificadas como melhores porque mais lidas (e citadas, o modo de se saber se são mais lidas) e mais citadas porque mais lidas. Não se vê necessidade de maior aprofundamento nas demais condições (e que são muitas!) que determinam a preferência de leitura, ou da citação, isto é, na categorização assumida. Ora, já se nota que, no mínimo, o processo é circular em sua essência, pela retroalimentação reverberativa, virtuoso se considerado por quem já possui o bom conceito; vicioso, por quem pretende a ele chegar. De qualquer modo, uma primeira questão já poderia ser suscitada quanto à objetividade do critério da qualificação "utilitarista": para um país como o nosso, melhor é o "universal", isto é, o trabalho que interesse a todo o mundo (e, indiretamente, também a nós, nele inserido)? Ou o que é "particular", o primordialmente voltado às nossas realidades e requerimentos mais prementes? Em síntese, competir (certamente em desvantagem) para crescer, ou crescer para competir?

Mas deixando de lado essa questão preliminar, pois já está resolvido que devemos nos comportar como valentes, isto é, que devemos competir em pé de igualdade com os mais fortes; ou ser "generosos", produzindo para o mundo, embora, frequentemente, muitos de nossos interesses mais imediatos fiquem relegados a segundo plano, o resultado é o de que a produção científica nacional canaliza-se em uma direção "universal" e as revistas nacionais às quais a melhor publicação não é preferencialmente oferecida ficam com as sobras.

Sobretudo, os critérios adotados pela CAPES, importantíssima agência de fomento de nossa produção científica, por suas avaliações do sistema nacional de ensino de pós-graduação estrita (Doutorado e Mestrado) influenciam, direta e indiretamente, os centros mais avançados de pesquisa científica em nosso país, formulando, por consequência, as políticas de progressão acadêmica brasileira como um todo: Universidades passaram a se servir dos mesmos modelos de avaliação.

Está cabalmente provado um inequívoco aumento da produção científica brasileira nos últimos anos, tanto em qualidade como em quantidade, segundo vários índices. Embora não esteja formal e definitivamente comprovada a correlação entre essa melhora e a assunção dos critérios de avaliação adotados pela CAPES e Universidades, é bem admissível que isso possa ser provado. Mas ainda que tal conclusão seja a verdadeira (o que também não necessariamente significa que isso tenha contribuído para melhorar o país), não parece haver justificativas para que esses critérios sejam exacerbados.

Pois é o que está acontecendo. Em tom de repúdio e protesto a tais decisões de política universitária (não apenas a do ensino de pós-graduação estrita, como à primeira vista parece) no Brasil, um excelente Editorial da revista "Clinics" (brasileira, apesar do nome, editada a cada dois meses pela Faculdade de Medicina da Universidade de São Paulo), assinada por seu Editor, Maurício Rocha e Silva ${ }^{1}$, um de nossos mais respeitados cientistas, renova as esperanças de que esse estado de coisas possa, afinal, começar a mudar. E alinhados com esse pensamento, associamo-nos às advertências nele contidas, reproduzindo partes de seu conteúdo, com a pretensão de 
poder ampliar seus efeitos. O título do Editorial já é elucidativo por si mesmo: "O novo Qualis, ou a tragédia anunciada". Nele se ressalva que a análise possa não estar suficientemente capacitada "para outras áreas, mas o produto oferecido à consideração da comunidade médica merece comentários". Em seguida, examina as premissas das alterações em implantação e as previstas consequências. No que interessa às revistas, elas passam a ser divididas em sete níveis, mas "de tal modo a assegurar que apenas $25 \%$ dos periódicos estejam no nível mais alto (Qualis A) e que haja maior número de periódicos A2 que Al”. Ou seja, para atingir o nível mais elevado, não basta que a revista seja boa. Ela deve ser melhor do que a maioria das boas.

A Oftalmologia encaixa-se entre as "subject category" do sistema ISI-JCR da área de Medicina I; das 14 categorias analisadas, a única que não chegaria sequer a completar os $25 \%$ de periódicos no primeiro nível Qualis é ... a Oftalmologia (apenas $4 \%$ dos periódicos com os maiores fatores de impacto atingiriam o nível A1). Na área de Medicina III (oito categorias analisadas), a Oftalmologia teria, entre seus (45) periódicos com os maiores fatores de impacto (FI), apenas $13 \%$ deles atingindo o nível A1 (FI > 3,0), 22\% deles ficando no nível A2 $(3,0 \geq \mathrm{FI}>1,8)$ e $47 \%$ no nível B1 $(1,8 \geq \mathrm{FI}>0,8)$. Mas, independentemente do maior rigor exigido para que se chegue aos melhores níveis, o problema da assunção do fator de impacto como "o" critério de avaliação das revistas científicas, comparando-as, deriva do fato de que "diferentes áreas do conhecimento atraem referências de modo diferenciado", o que acarreta desequilíbrios ao considerar como potencialmente equivalentes os fatores de impacto de disciplinas heterogêneas. Uma das conclusões interessantes é a de que "um pesquisador brasileiro pode ganhar o Prêmio Nobel por uma descoberta em otorrinolaringologia e não conseguir a glória caseira de um Qualis A1!", porque nenhuma revista de Otorrinolaringologia em todo o mundo (!) chegaria a alcançar esse nível na nova proposta da CAPES...

Além disso, ao tratar especificamente dos periódicos brasileiros, o texto afirma que "a diferença de citação é maior que a diferença de qualidade", para significar que uma publicação de boa qualidade publicada em revista estrangeira terá mais citações (maior "impacto") que se publicada numa brasileira. Ou que um artigo publicado em revista brasileira, apesar de um impacto menor, pode ter qualidade melhor do que outro, cujo fator de impacto é maior, apenas por ser publicado em periódico estrangeiro. A propósito, o autor daquele editorial menciona estar participando de debates no congresso anual do próximo ano do Council for Science Editors dos Estados Unidos, com temas provocativos como o de "Citations are how we evaluate published science. Citations have differential properties intrinsically related to subject area, journal visibility, geographic origin, language. How do we bridge these gaps?" Ou seja, não são apenas "brasileiros" a reconhecer a iniquidade dos critérios tão desastrosamente propostos pela CAPES. Sobre os quais ele conclui: "É pois evidente que a CAPES não deveria apoiar os periódicos brasileiros com a mão direita do financiamento e prejudicá-los com essa anunciada mão do novo Qualis. A nova tabela exclui radicalmente a totalidade das revistas brasileiras até mesmo do Qualis A2. Realisticamente, não creio que existam revistas brasileiras Qualis A1." ... "Os níveis propostos parecem altos demais ... (aplicando-se) ... método tipo Harvard ao sistema brasileiro ... sem (os propositores da idéia) se darem conta que ainda temos que crescer um bocado antes de encarar Harvard de igual para igual".

E para terminar, uma visão que naturalmente parece fora de moda nos tempos de globalização, mas que não perdeu seu vigor e validade: "Finalmente, um pouco de patriotismo sadio nunca fez mal a ninguém (perguntem aos americanos): algum suporte aos periódicos brasileiros é imperativo. Não estou sugerindo que se escancare a porteira: apenas que se dê aos periódicos brasileiros metas atingíveis de ambição de progresso."

Nós também!

\section{AGRADECIMENTO}

A Regina de Souza Carvalho, por nos haver alertado para esse Editorial.

\section{REFERÊNCIA}

1. Rocha-e-Silva M. O novo Qualis, ou a tragédia anunciada. Clinics (São Paulo). 2009;64(1):1-4. 